\title{
18. Between formal openness and stratification in secondary education: Implications for social inequalities in Italy
}

\section{Dalit Contini and Moris Triventi}

\section{INTRODUCTION}

Educational choices in Italy are plagued by large inequalities related to social origin. The crucial point is the transition to upper secondary school. This occurs typically at age 14 when children leave comprehensive education and choose among a variety of educational programmes with different curricular content and learning targets. The existing literature shows consistently that whereas the majority of children with high social origin attend upper secondary schools in the academic track, children with low parental education or in the working class are much more likely to attend technical and vocational schools (Gambetta 1987; Cavalli and Facchini 2001; Schizzerotto and Barone 2006; Checchi and Flabbi 2007; Contini and Scagni 2013). Despite the educational expansion, social segregation in upper secondary schooling choices has further increased in the second half of the twentieth century (Panichella and Triventi 2014).

Higher education participation has always been low in Italy relative to most other industrialized countries. University entry rates increased substantially with the implementation of the 'Bologna process' - aimed at harmonizing higher education systems across the EU - that introduced shorter bachelor programmes in 2001. However, graduation rates are still far below the OECD average (OECD 2014). In addition, the socio-economic gradient in enrolment and completion rates is large (Recchi 2007; Triventi and Trivellato 2009). Enrolment inequalities dropped slightly after 2001 (Cappellari and Lucifora 2009) due to higher entry rates among high-ability children from the lower classes, but this trend has been only temporary (Argentin and Triventi 2011; Ballarino and Panichella 2014). 
Social origin differentials in choices relative to upper secondary and tertiary education seem to be considerably wider in Italy than in other European countries (Jackson 2013) even in relation to other stratified educational systems such as Germany or the Netherlands (Checchi and Flabbi 2007; Contini and Scagni 2011). Effects given prior achievement - the socalled secondary effects - are also large (Contini and Scagni 2013; Jackson 2013): social origin influences educational choices well beyond the effect due to the better performance of children with more advantaged backgrounds.

Interestingly, in a comparative perspective, inequalities look sharply different when we move from educational choices and attainment to achievement. Looking at PISA scores, the socio-economic gradient is relatively small in Italy and much closer to egalitarian Finland than to Germany, Great Britain, or France (OECD 2014). This evidence is puzzling. Given the existence of large social origin inequalities in school choices, and the marked differences in learning standards between upper secondary educational programmes, we would also expect large achievement differentials.

Against this background, this chapter aims to outline a comprehensive overview of social background educational inequalities in Italy from the beginning of upper secondary schooling up to tertiary education enrolment. We attempt to overcome some limitations of existing research, update results, or offer additional descriptive findings on topics for which the existing evidence is scant. We focus on inequalities in educational choices and more specifically on inequalities in (1) upper secondary school attendance in the different tracks (RQ1), (2) upper secondary school dropout (RQ2), (3) track changes (RQ2), and (4) higher education enrolment (RQ3). In addition, we examine inequalities in reading and math test scores in 10th grade. All analyses are performed conditionally and unconditionally on prior school performance in order to assess how far the observed gaps are due to mechanisms operating over and beyond the poorer prior achievement of pupils with a lower social background.

\section{THE ITALIAN EDUCATIONAL SYSTEM}

In the past decades, the Italian schooling system has undergone several detracking reforms aimed at increasing participation and reducing social inequalities. In 1963, lower secondary education, formerly divided into general education and a vocational dead end track, became comprehensive (scuola media unica) and the minimum school-leaving age was raised to 14 . Access to tertiary education, previously limited to students with an academic diploma, was extended to all students with a five-year upper secondary 
qualification in 1969. In 2006, the minimum school-leaving age was raised to 16 , so the majority of students now attend at least two years of upper secondary education.

In the current system, students attend eight years of comprehensive education composed of five years of primary school (age 6-11) and three years of lower secondary education (age 11-14). Upper secondary education starts at 14 and lasts five years. Students choose among a variety of school types offering considerably different educational programmes. These programmes are classified into three broad tracks: the academic track (licei), the technical track (istituti tecnici), and the vocational track (istituti professionali). In addition to state-level education, students can opt for 2-4 year vocational training programmes (formazione professionale) provided on the regional level and closely linked to local labour market needs. ${ }^{1}$ Despite the strongly stratified character of the Italian upper secondary education system, there are no ability restrictions regulating access to the different educational programmes. Moreover, all students with a five-year diploma have access to tertiary education.

Tracks differ markedly in terms of curricula, institutional purposes, academic standards, and prestige. Lyceums provide general and academically oriented curricula; they are widely considered to be the main route to university. Technical institutes prepare students for technical occupations in economic or technological sectors, whereas vocational schools provide practical instruction preparing for lower level technical jobs. ${ }^{2}$ Further differences exist within tracks. Within the academic track, for example, students may choose between programmes emphasizing the humanities, scientific subjects, foreign languages, or the arts (the first two are widely considered to be substantially more demanding than the latter).

As mentioned above, children may choose freely among these different school types. Lower secondary school teachers formulate recommendations, but they are not binding and families often ignore them. Students may change school and educational programme, but they need the authorization of the receiving institution. In practice, as we shall show, the majority of school changes are towards less demanding educational programmes and are usually a result of children's poor performance.

After obtaining a five-year upper secondary diploma, individuals may enter higher education. In general, there are no entry restrictions to the university system, although access to a few degree programmes is limited and regulated by ability-based entry tests. The Italian higher education system is composed largely of public universities, and there is no formal divide between academic programmes and polytechnic programmes aimed at preparing intermediate-level executives. Before 2001, the institutional length of degrees varied between four and six years. With the implementation of the 
'Bologna process', the system has been organized into a three-year bachelor programme followed by a two-year master programme (with the exceptions of a few majors in the law and medical schools that still last 5-6 years).

Table 18.1: Variables used in the analyses in each dataset

\begin{tabular}{|c|c|c|c|}
\hline & INVALSI 2013/14 & IARD 2000 & ISTAT 2011 \\
\hline & \multicolumn{3}{|c|}{ Socio-demographic variables } \\
\hline Parental education & \multicolumn{3}{|c|}{$\begin{array}{l}\text { University; Upper secondary; } \\
\text { No more than lower secondary education }\end{array}$} \\
\hline Gender & \multicolumn{3}{|c|}{ Male; Female } \\
\hline Geographical area & \multicolumn{3}{|c|}{ North-West; North-East; Centre; South; Isles } \\
\hline Year of birth & - & $\begin{array}{c}1965-69 ; 1970-74 \\
1975-80\end{array}$ & - \\
\hline \multirow[t]{2}{*}{ Migration status } & $\begin{array}{l}\text { Italian; } 2 \mathrm{nd}- \\
\text { generation migrant }\end{array}$ & - & - \\
\hline & \multicolumn{3}{|c|}{ Education-related variables } \\
\hline \multirow[t]{2}{*}{ High school track } & \multicolumn{3}{|c|}{ Academic/General; Technical; Vocational } \\
\hline & $\begin{array}{l}\text { Track in } \\
\text { 10th grade }\end{array}$ & 1 st track & $\begin{array}{c}\text { 1st track } \\
\text { (only for high } \\
\text { school graduates) } \\
\text { plus track of } \\
\text { diploma }\end{array}$ \\
\hline $\begin{array}{l}\text { Final mark in lower } \\
\text { sec. education }\end{array}$ & $\begin{array}{l}6 \text { (low); } \\
9 / 10 \text { (high) }\end{array}$ & \multicolumn{2}{|c|}{$\begin{array}{l}\text { Sufficient; Good; } \\
\text { Very good; Excellent }\end{array}$} \\
\hline $\begin{array}{l}\text { Performance in } \\
\text { standardized test } \\
\text { in upper sec. } \\
\text { education }\end{array}$ & $\begin{array}{c}\text { 10th grade } \\
\text { test scores in: } \\
\text { Italian } \\
\text { (range: }-85 ; 408 \text { ); } \\
\text { Math } \\
\text { (range: }-40.8 ; 426.3 \text { ) }\end{array}$ & - & - \\
\hline $\begin{array}{l}\text { Final mark in upper } \\
\text { sec. education }\end{array}$ & - & - & $\begin{array}{l}\text { 60-69; 70-79; } \\
80-89 ; 90-100\end{array}$ \\
\hline Enrolment & - & - & $\begin{array}{c}\text { Enrolment in } \\
\text { university within } 4 \\
\text { years after diploma }\end{array}$ \\
\hline Dropout & - & $\begin{array}{l}\text { Dropout from high } \\
\text { school (among } \\
\text { those aged } 20 \text { or } \\
\text { more) }\end{array}$ & - \\
\hline
\end{tabular}

Source: Own illustration. 


\section{DATA AND VARIABLES}

Regrettably, Italy lacks a unified micro-data archive on schooling careers. Therefore, we shall have to exploit different data sources covering various stages of the schooling career and different birth cohorts.

The first archive comes from the National School Assessment Programme (INVALSI-SNV), and provides information on the population of students enrolled in 10th grade (i.e. second year of upper secondary education) in 2013-14. Data include standardized test scores on Italian and Mathematics, information on family background, and information on the school. The analytical sample includes 31265 students. ${ }^{3}$ We exploit these data to study the students' allocation into the different tracks and to analyse achievement across tracks and social origin.

The second data source comes from the 'Survey on the Youth Condition' by the IARD Institute in 2000 that retrospectively interviewed individuals aged 15-35 on different aspects of the youth condition and educational careers. We use these data to draw information on upper secondary school dropout by exploiting the information provided by individuals aged 20-35. The birth cohorts involved in this data archive are rather old. However, due to the lack of appropriate data, analysing early school leaving in Italy is difficult; this archive is the only source providing detailed information on social origin and prior performance. The analytical sample contains 1967 students.

The third data source is the Survey of High-School Graduates (2011), carried out by the Italian National Statistical Institute (ISTAT) on individuals who attained the upper secondary diploma in 2007. It focuses on labour market participation and access to tertiary education. The analytical sample size is 26038 . We use this dataset to analyse changes across tracks in upper secondary school and transition to higher education.

The variables employed in the empirical analyses in each data source are reviewed in Table 18.1, whereas the birth cohorts involved are to be found in Figure A1 in the online appendix (Contini and Triventi 2016).

\section{EMPIRICAL RESULTS}

\section{Track Placement in Upper Secondary Education}

Following the literature on primary and secondary effects, Contini and Scagni (2013) decomposed social background differentials in the probability of choosing the academic track in upper secondary school into components related to the indirect effect of social origin via prior performance and the direct effect net of prior performance. They used various editions of the Istat Survey of High School Graduates, adjusting for sample selection, to account 
Table 18.2: Distribution of school track in 10th grade according to highest parental education and lower secondary mark (row percentages)

\begin{tabular}{lcccc}
\hline \multicolumn{4}{c}{ School track in 10th grade } \\
\hline \multicolumn{1}{l}{ Lyceums } & Technical & Vocational & Total \\
\hline Highest parental education & & & & \\
$\quad$ University & 70.7 & 20.7 & 8.6 & 100.0 \\
$\quad$ Upper secondary & 44.6 & 37.3 & 18.1 & 100.0 \\
Lower secondary & 24.8 & 38.1 & 37.0 & 100.0 \\
Lower secondary mark & & & & \\
6 & 14.7 & 36.5 & 48.8 & 100.0 \\
7 & 29.5 & 44.4 & 26.1 & 100.0 \\
8 & 54.1 & 35.9 & 10.0 & 100.0 \\
$9 / 10$ & 79.1 & 17.3 & 3.6 & 100.0 \\
Total & 46.4 & 33.6 & 19.9 & 100.0 \\
$\mathrm{~N}$ & 14514 & 10518 & 6233 & 31265 \\
\hline
\end{tabular}

Source: Own calculations based on data from Invalsi (2013-14).

for the fact that high school dropouts were not interviewed. Secondary effects accounted for more than 50 per cent of the total differentials. Ress and Azzolini (2014) found similar results when analysing a unique local administrative longitudinal data archive from the Province of Trento.

In this chapter, we exploit the data of the national learning assessment on 10th graders (INVALSI, 2013-14) - the first release providing information on pre-tracking performance (the grade obtained at the lower secondary school final examination). Because we analyse the school type attended in 10th grade, we look at the result of a process including (endogenous) choice revisions possibly due to poor performance or dissatisfaction with the educational programme.

The results of multinomial regression models in terms of odds ratios (OR) and average partial effects (APE) are shown in Tables A2-A3 in the online appendix (Contini and Triventi 2016). The gross OR of entering the academic versus the vocational track when comparing students with tertiary educated parents with those with compulsory education is 15 percentage points (Model 1 ), and the corresponding APE is 47 percentage points. This figure reduces but remains large (33 percentage points) after controlling for prior marks (Model 2). Similarly, the probability of attending technical versus vocational education increases with parental education. Previous school achievement is the main predictor of track placement: net of parental education, the odds of attending the academic track versus vocational education among those with very good marks (9-10) is more than 50 times that of children with only a 'pass' grade (6). 

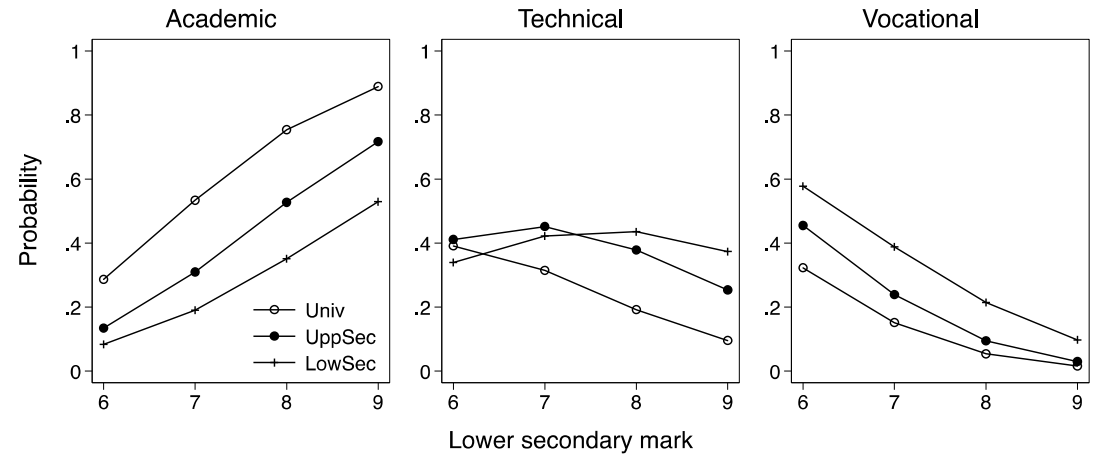

Figure 18.1: Multinomial logistic regression of probability of track placement in 10th grade: predictive margins from a model with interaction between parental education and lower secondary education final mark

Source: Own calculations based on data from Invalsi (2013-14).

Next, we analyse whether parental education effects differ by prior school marks. Sizable interaction effects exist (Figure 18.1). Students with highly educated parents have a higher probability of attending the academic track at all performance levels. Instead, the probability of attending the technical track differs little among low-performing students of different social origins, whereas among high-performing students, it is larger for those with loweducated parents. Vocational education is very common among poor performing students of low social origin, but much less common among poor performing students with tertiary educated parents. High-performing students rarely choose vocational education, although the share is non-negligible (10 per cent) among those with low parental education. ${ }^{4}$

Finally, we decompose total inequalities into primary and secondary effects using the KHB method (Karlson and Holm 2011). Our findings, reported in Table 18.3 confirm previous research indicating that secondary effects account for more than one-half of the entire social background differentials. More specifically, when comparing the academic and technical tracks, only 29 per cent of the differential between high and low parental education and 39 per cent of the differential between high and medium parental education can be ascribed to differences in prior achievement (the corresponding figures when comparing the technical and vocational tracks are 50 per cent and 37 per cent). Hence, 50-71 per cent of the total differentials are due to the effect of other mechanisms. 
Table 18.3: KHB decomposition analysis: primary effects as a percentage of the total effects (odds ratios) of parental education on track placement in 10th grade

\begin{tabular}{lccc}
\hline & $\begin{array}{c}\text { Lyceum vs } \\
\text { vocational }\end{array}$ & $\begin{array}{c}\text { Lyceum vs } \\
\text { technical }\end{array}$ & $\begin{array}{c}\text { Technical vs } \\
\text { vocational }\end{array}$ \\
\hline Parental education & & & \\
Lower secondary vs university & 35.7 & 28.6 & 50.5 \\
Upper secondary vs university & 38.0 & 39.0 & 36.8 \\
\hline
\end{tabular}

Source: Own calculations based on data from Invalsi (2013-14).

\section{Upper Secondary School Dropout}

Because upper secondary education ends at age 18-19 whereas compulsory schooling is up to age 16, many children exit the schooling system without attaining a high school qualification. Indeed, some children do not even complete compulsory schooling. According to Eurostat (2016), the share of the population aged 18-24 with at most lower secondary education and not in further education or training has been declining constantly over the past decades, but it was still 17 per cent in 2013 - among the highest in Europe.

The existence of dramatic differences related to parental education in early school leaving has been shown by Borgna and Struffolino (2014). Dropout is highly related to grade retention: children repeating a school year are much more likely to withdraw at an early age (Mocetti 2012). ${ }^{5}$

Focusing on dropout after the beginning of upper secondary school, we complement the existing evidence by analysing early school leaving by parental education and prior school performance. We assess the extent to which family background affects dropout and whether its effect is fully mediated by achievement. To this end, we employ the Survey on Youth Conditions 2000 (IARD) that provides information on lower secondary final examination marks. The limitation is that it refers to rather old birth cohorts (1965-80). Summarizing descriptive statistics, we found that more than 7 per cent of the students in the sample left school without a diploma (Table A8 in the online appendix, Contini and Triventi 2016). This share changes across the tracks students first enrolled into: 3.2 per cent for the academic track, 6.4 per cent for the technical track, and 19.7 per cent for the vocational track.

We analyse the dropout risk using binomial logistic regression models (see Table A9 in the online appendix, Contini and Triventi 2016). Although prior school performance is the main predictor of dropout, social background inequalities are marked: the gross dropout odds are almost 11 times higher among students with low-educated parents than among those with higheducated parents (Model 1). Differentials by parental education are explained 

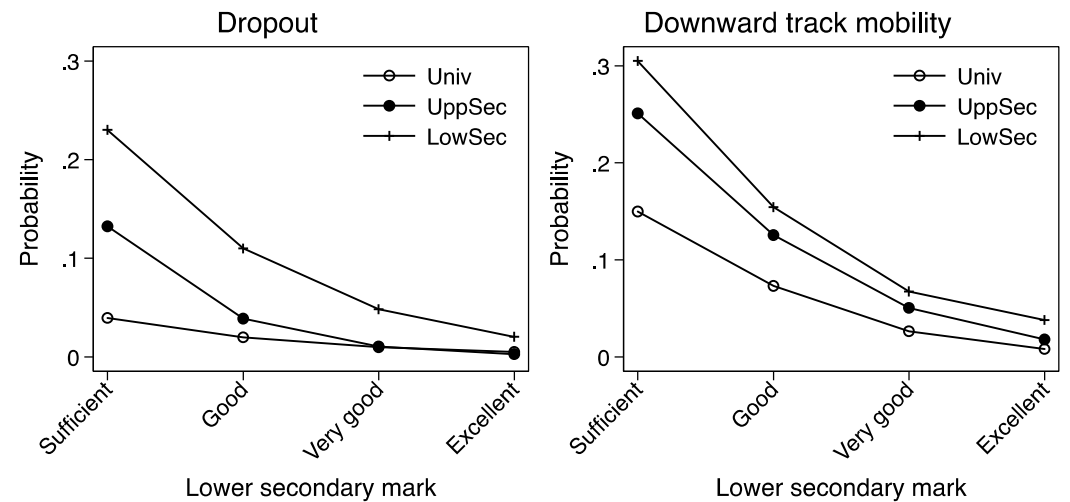

Figure 18.2: Binomial logistic regression of probability of dropout (left) and downward track mobility from the academic track (right): predictive margins from the interaction between parental education and lower secondary education mark

Source: Own calculations based on data from Iard (2000) and Istat (2011).

only partly by achievement: given the final examination mark at lower secondary school, the OR between high and low educated parents is 5.9 (Model 2). These results do not change substantially when accounting for track at first enrolment (Model 3).

Among very low-performing students, predicted dropout probabilities vary between 3-4 per cent for high parental education and 23 per cent for low parental education. Whereas the dropout probability is nearly zero among well-performing students from the medium-high social strata, it is nonnegligible among the well-performing students of the lowest stratum (Figure 18.2 , left panel). ${ }^{6}$

\section{Mobility across Tracks}

What happens at entrance into upper secondary education? Can students change school types easily, or are there strong barriers across tracks? Do we observe only descending track mobility, or do children also upgrade their initial choice? We provide some descriptive evidence on the permeability of track barriers and the direction of changes by exploiting the latest wave of the Survey on High-School Graduates (ISTAT). The data include the school type individuals chose immediately after the end of lower secondary school and the school type at graduation. Hence, these data allow us to examine only school type changes of individuals who successfully completed upper secondary education. ${ }^{?}$ 
In this exercise, we define mobility by comparing track of entrance with track of diploma. Horizontal changes (within-track) are not considered. A total of 4.7 per cent of high school graduates changed track during upper secondary education. Track changes were more frequent among students who first entered the academic track (6.1 per cent), followed by those who first entered vocational education (4.2 per cent) and technical education (3.2 per cent) (Table A10 in the online appendix, Contini and Triventi 2016).

Downward mobility is more frequent than upward mobility (3.8 per cent vs 0.9 per cent). Hence, although formal changes between educational programmes are possible, it is very difficult to upgrade initial choices and move to programmes with a higher academic content. Closer moves (academic-technical and technical-vocational) are more frequent: among the high school graduates who first entered the academic track, 4.2 per cent moved to technical education and only 1.9 per cent to vocational education.

We then use logit regression to analyse downward mobility among children who first entered the academic track (Table A11 in the online appendix, Contini and Triventi 2016). Parental education relates negatively to downward track mobility: the gross OR between students with low and high parental education is 3.5 (Model 1). The OR given lower secondary school marks is 2.7 (Model 2). Absolute probability differentials by parental education are much larger for low-performing students than for highperforming students (Figure 18.2, right panel).

\section{Transition to University}

Despite the expansion of the educational system and the university reform originating from the Bologna Process, socio-economic differentials in university enrolment rates are still very large. Considering the most recently available data on high-school graduates (2007 cohort), the enrolment probability differential between children with high and low parental education is 39 percentage points, and that between children with high and medium parental education is 14 percentage points (Table A13 in the online appendix, Model 1). These inequalities are driven largely by differences in upper secondary schooling. Students who obtained a diploma in the academic track have a probability of making the transition to university that is 54 percentage points higher than that of students with a vocational diploma and 33 percentage points higher than that of students with a technical diploma. Given the huge inequalities in track choices, social origin differentials in the probability of university enrolment are more than halved when controlling for the type of track (Model 2). Instead, the high-school final examination mark, although statistically significant and relevant in size, does not contribute much to the explanation of social origin differentials (Model 3). 

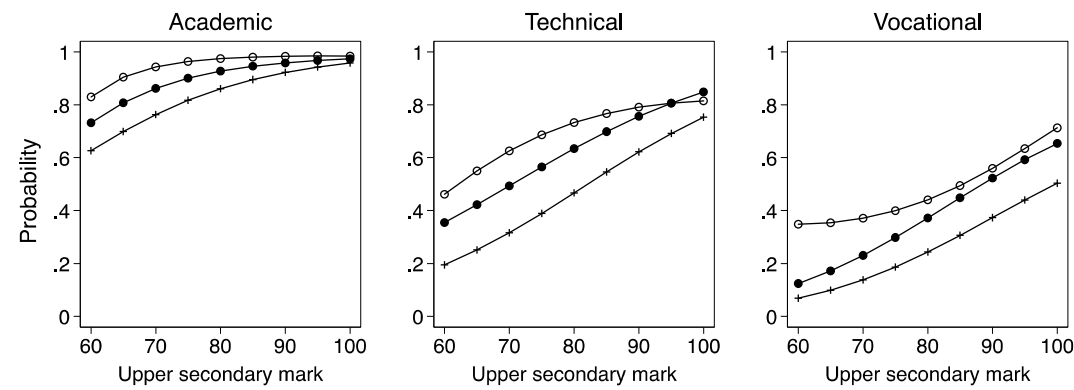

Highest parental education

$\multimap$ Univ $\longrightarrow$ UppSec $\longrightarrow$ LowSec

Figure 18.3: Binomial logistic regression of probability of entering university within four years after diploma: predictive margins from the interaction between parental education and upper secondary education mark

Source: Own calculations based on data from Istat (2011).

Figure 18.3 depicts the predicted probability of university enrolment conditional on upper secondary school track and final examination mark. Enrolment rates reflect the highly stratified character of the Italian upper secondary education system. Nearly all students with an academic degree and a very high mark make the transition to tertiary education regardless of social origin. However, family background is an important driver of university participation among lower performing students and students from the less prestigious tracks.

Considering technical and vocational school graduates, the university enrolment gap between high and medium parental education is sizable at low grades and small or zero at high grades, whereas the gap between medium and low parental education is always substantial.

\section{Achievement in Upper Secondary Education}

In this section, we focus on achievement in upper secondary school as measured by a national-level standardized assessment of Italian (reading comprehension and use of language) and Mathematics in 10th graders almost two years after tracking. Simple descriptive evidence resulting from linear regression is presented in Table 18.4. As expected, achievement differentials across tracks are large (Model 1). On average, a child on the academic track obtains approximately 20-25 points (half a standard deviation) more than a similar child on the technical track (with slightly lower differentials in Math 
than in Italian), and around 45 points more than a child on the vocational track.

The differential between children of high and low parental education is 26 points in Italian and 23 points in Math - that is 0.6-0.7 standard deviations (Model 2). ${ }^{8}$ If we examine inequalities within tracks (Model 3), the parental education gap decreases to $8-9$ points (above 0.2 standard deviations), whereas when we also control for prior performance (Model 4), it goes further down to 4 points in Italian and 2.5 in Math. These are small but nonnegligible differentials.

Consistent with the different curricula and learning targets, the performance gap between tracks remains large even after controlling for individual socio-demographic characteristics and prior achievement (Model 4). In the Italian test, children on the general track obtain 13 points $(0.3$ standard deviations) more than children on the technical track, and 26 points (0.6 standard deviations) more than those on the vocational track. Differentials are somewhat smaller for Math test scores.

Table 18.4: Linear regression of standardized test scores in Italian and mathematics

\begin{tabular}{|c|c|c|c|c|}
\hline & Model 1 & Model 2 & Model 3 & Model 4 \\
\hline & \multicolumn{4}{|c|}{ Italian } \\
\hline \multicolumn{5}{|c|}{ Parental education (ref. University) } \\
\hline Upper secondary & & $-11.2 * *$ & $-3.0 * *$ & -0.7 \\
\hline Lower secondary & & $-26.3 * *$ & $-9.3 * *$ & $-4.1 * *$ \\
\hline \multicolumn{5}{|l|}{ Track (ref. General) } \\
\hline Technical & $-25.6 * *$ & & $-23.4 * *$ & $-13.0 * *$ \\
\hline \multirow[t]{2}{*}{ Vocational } & $-47.5^{* *}$ & & $-43.5^{* *}$ & $-26.2 * *$ \\
\hline & \multicolumn{4}{|c|}{ Mathematics } \\
\hline \multicolumn{5}{|c|}{ Parental education (ref. University) } \\
\hline Upper secondary & & $-10.5 * *$ & $-3.5^{* *}$ & -1.1 \\
\hline Lower secondary & & $-23.3 * *$ & $-8.0 * *$ & $-2.5^{*}$ \\
\hline \multicolumn{5}{|l|}{ Track (ref. General) } \\
\hline Technical & $-19.1 * *$ & & $-17.6^{* *}$ & $-6.7 * *$ \\
\hline Vocational & $-44.4 * *$ & & $-41.9 * *$ & $-23.8^{* *}$ \\
\hline
\end{tabular}

Source: Own calculations based on data Invalsi (2013-14).

Notes: $+p<0.10, * p<0.05, * * p<0.01$. Standardized scores: population mean $=200$ and standard deviation $=40$. Cluster robust standard errors (clusters $=$ classes). Controls in all models: gender, geographical area, migrant status (1st-generation migrants excluded). Model 4 additionally controls for final mark in lower secondary school. 
In a very loose sense, we could think of these figures as relative 'valueadded' measures of attending the different tracks (yet, this should be taken as a very rough indication, because unobservable personal traits - motivation or innate cognitive ability - are likely to operate, leading to overestimation of the added value). ${ }^{9}$ These results would corroborate the common knowledge that the different educational programmes offer substantially different learning opportunities.

\section{CONCLUSIONS}

Overall, we may draw the following conclusions. First, even in recent cohorts, social origin plays a decisive role in educational outcomes. Students from higher level backgrounds obtain better results in terms of school performance and achievement tests and make more prestigious school choices. They are more likely to enter the academic track and, later on, to attend university, and they are less likely to make downward moves to less demanding educational programmes and withdraw from upper secondary education.

Second, social origin differentials are mediated only partially by school performance. This result holds for upper secondary school choices, dropout, mobility across tracks, and university attendance. We may conclude that social origin plays a major role in determining educational choices after compulsory school that goes well beyond ability differences.

In particular, we confirm earlier findings that the effect of social origin on the upper secondary school track is mediated only partially by prior performance: secondary effects account for 50-71 per cent of the observed differentials. Consequently, social segregation in the Italian upper secondary school system is substantial: the student body composition varies greatly across schools in terms of achievement but also in terms of the social fabric (see Table A1 in the online appendix, Contini and Triventi 2016).

Despite the socially selective process involving upper secondary school attendance, track mobility, and school dropout, social background plays a role even after the attainment of an upper secondary diploma. Higher education enrolment obviously depends strongly on the high school type. However, the enrolment probability is substantially higher for children of advantaged backgrounds even when comparing pupils who attended the same track and obtained similar grades.

Third, our findings support the evidence that barriers across tracks are very strong in Italy: downward mobility is rather common, most likely because of poor scholastic performance, whereas upward moves are rare. 
Fourth, despite the system's openness in terms of absence of ability barriers in the key school transitions, the transition to upper secondary school emerges as a crucial turning point in children's lives - particularly for those of low social origin. Consider the transition to university for young individuals of low parental education: the proportion of university entrants among the students who obtained a poor mark (6-7) in the final lower secondary examination and graduated from the academic track is 73 per cent. The share goes down to 52 per cent among those who obtained a very good mark (9-10) but graduated from the technical track, and to 30 per cent among those who obtained a very good mark but graduated from the vocational track (our elaboration on data from Istat 2011). Even though these figures cannot be interpreted in causal terms, they do suggest that - whether due to anticipatory effects or to the influence of peers, teachers, and the learning process - the upper secondary school choice may make a life-long difference for the children of disadvantaged social groups.

Last, we provide our interpretation of the puzzling evidence that, in a comparative perspective, Italy stands out as a country with extremely large social origin inequalities in educational choices but relatively small achievement differentials in international assessments. According to the PISA study, Italy ranks rather poorly in all competence domains and has only few excellent scores. This evidence is consistent with a picture in which, despite the indubitable differences in curricula and learning standards across school types, the share of low-performing children in lyceums is large and the INVALSI test score distributions of different tracks are largely overlapping (Figure A4 in the online appendix, Contini and Triventi 2016).

A potential explanation lies in the coexistence of high stratification and full openness of the educational system. Access to the different upper secondary educational programmes is completely open, fully resting on families' decisions. Even access to tertiary education - characterized mostly by public universities - is usually not conditional on ability requirements. Hence, there are no strong external incentives for children to achieve well, because performance plays no major role in eligibility to the academic track and university.

However, there is a widespread opinion that the academic track represents a kind of 'natural choice' for children with a high social background. If they perform poorly, these students might gain additional support (parent's direct involvement, private lessons, etc.), settle for low grades, or move to less demanding schools. These suboptimal alternatives do not prevent them from enrolling at university. Furthermore, the children from advantaged backgrounds may rely on high-quality social capital as an additional key resource for finding a job in the Italian labour market that is characterized by a widespread use of personal ties in recruitment processes (Reyneri 2005) - 
even on the high skills level (Rostan 2006). The case is different for students from disadvantaged backgrounds who normally choose the academic track and enter university only if they perceive themselves to be high performing or if they have particularly high aspirations of upward mobility.

All things considered, the mix between the formal openness and the de facto high stratification of the Italian educational system may be a bad recipe for equality (and efficiency). On the one side, a strong divide in upper secondary educational programmes at an early age is likely to promote educational inequalities (e.g. Schütz et al. 2008); on the other side, ability restrictions are not necessarily detrimental to equality of opportunity (Contini and Scagni 2011). We are not advocating the enforcement of access restrictions in the Italian educational system. However, we do think that an extension of comprehensive education and compulsory schooling, together with some ability screening at university entrance, may represent an effective way to reduce inequalities and provide incentives for better learning.

\section{NOTES}

1 Only a small minority of students choose regional vocational education, but regional variations are large.

2 Vocational education also offers a first qualification after three years that does not give access to higher education.

3 The assessment involves the entire population of 10 th graders. However, to avoid bias due to cheating, we analyse the random subsample taking the test under the supervision of external observers. First-generation migrant children are excluded from the analyses.

4 Detailed results are reported in Tables A6-A7, and in Figure A2 in the online appendix, Contini and Triventi (2016)

5 Grade retention is common: it is considered as a correct sanction for disruptive behaviour and poor school involvement, and a tool to help low-performing students catch up and overcome the learning gap.

6 Detailed results are given in Table A12 and Figure A3 in the online appendix, Contini and Triventi (2016).

7 If descending track changes are more frequent among low-performing students, the exclusion of dropouts is likely to yield conservative estimates of the incidence of descending track mobility.

8 This result is in line with evidence from the PISA data (authors' elaborations).

9 In this sense, the reported figures should be considered as upper bounds of the true added value.

\section{REFERENCES}

Argentin, G. and M. Triventi (2011), 'Social inequality in higher education and labour market in a period of institutional reforms: Italy, 1992-2007', Higher Education, 61 (3), 309-23. 
Ballarino, G. and N. Panichella (2014), 'Origini familiari, scuola secondaria e accesso all'università dei diplomati italiani, 1995-2007', Scuola democratica, 2, 365-92.

Borgna, C. and Struffolino, E. (2014), 'Early School Leaving Dynamics in Italy. The Heterogeneity of Gender Effects', ISFOL Research Paper 20 (ISSN 2281-499X).

Cappellari, L. and C. Lucifora (2009), "The "Bologna Process" and college enrollment decisions', Labour Economics, 16 (6), 638-47.

Cavalli, A. and C. Facchini (eds) (2001), Scelte cruciali. Indagine Iard su giovani e famiglie di fronte alle scelte alla fine della scuola secondaria. Bologna, Italy: Mulino.

Checchi, D. and L. Flabbi (2007), 'Intergenerational mobility and schooling decisions in Germany and Italy: The impact of secondary school tracks', IZA Discussion Paper No. 2876

Contini, D. and A. Scagni (2011), 'Inequality of opportunity in secondary school enrolment in Italy, Germany and the Netherlands', Quality and Quantity, 45, 44164.

Contini, D. and A. Scagni (2013), 'Social-Origin Inequalities in Educational Careers in Italy', in M. Jackson (ed.), Determined to Succeed? Performance versus Choice in Educational Attainment, Stanford, CA: Stanford University Press, pp. 149-184.

Contini, D. and M. Triventi (2016), Between formal openness and stratification in secondary education: Implications for social inequalities in Italy. Supplementary material at https://sites.google.com/site/edulifeproject2016/phase-3-secondaryeducation.

Eurostat (2016), Early leavers from education and training by sex, accessed 13 January 2016 at $\mathrm{http}: / /$ ec.europa.eu/eurostat/tgm/table.do?tab=table\&init=1\& language $=$ en\&pcode $=$ t2020_40\&plugin $=1$.

Gambetta, D. (1987), Were They Pushed or Did They Jump?, Cambridge, England: Cambridge University Press.

Istat (2011). Indagine sui percorsi di studio e di lavoro dei diplomati (Survey on high school graduates). Rome, Italy: Istituto Nazionale di Statistica.

Jackson, M. (ed.). Determined to Succeed? Performance versus Choice in Educational Attainment, Stanford, CA: Stanford University Press.

Karlson, K. B. and Holm, A. (2011), 'Decomposing primary and secondary effects: A new decomposition method', Research in Social Stratification and Mobility, 29 (2), 221-37.

Mocetti, S. (2012), 'Educational choices and the selection process: Before and after compulsory schooling', Education Economics, 20 (2), 189-209.

OECD (2014), Education at a glance, Paris, France: Organization for Economic Cooperation and Development.

Panichella, N. and M. Triventi (2014), 'Social inequalities in the choice of secondary school: Long-term trends during educational expansion and reforms in Italy', European Societies, 16 (5), 666-93.

Recchi, E. (2007), 'Italy: Expansion, reform, and social inequality in higher education', in Y. Shavit, R. Arum and A. Gamoran (eds), Stratification in higher education. A comparative study, Stanford, CA: Stanford University Press, pp. 400420.

Ress, A. and D. Azzolini (2014), 'Primary and secondary effects of social background on educational attainment in Italy. Evidence from an administrative dataset' Italian Journal of Sociology of Education, 6 (1), 53-80. 
Reyneri, E. (2005), Sociologia del mercato del lavoro. Il mercato del lavoro tra famiglia e welfare, Bologna, Italy: Il Mulino.

Rostan, M. (2006), Laureati italiani ed europei a confronto. Istruzione superiore e lavoro alle soglie di un periodo di riforme, Milano, Italy: Edizioni Universitarie di Lettere Economia Diritto.

Schizzerotto, A. and C. Barone (2006), Sociologia dell'istruzione, Bologna, Italy: Il Mulino.

Schütz, G., H.W. Ursprung and L. Wößmann (2008), 'Education policy and equality of opportunity' Kyklos, 61 (2), 279-308.

Triventi, M. and P. Trivellato (2009), 'Participation, performance and inequality in Italian higher education in the 20th century', Higher Education, 57, 681-702. 